\title{
Identifying Significant Cost-Influencing Factors for Sustainable Development in Construction Industry Using Structural Equation Modelling
}

\author{
Linlin Zhao $\mathbb{D}^{1}{ }^{1}$ Jasper Mbachu, ${ }^{2}$ and Zhansheng Liu ${ }^{1}$ \\ ${ }^{1}$ College of Architecture and Civil Engineering, Beijing University of Technology, Beijing 100124, China \\ ${ }^{2}$ Faculty of Society \& Design, Bond University, Gold Coast 4226, Australia \\ Correspondence should be addressed to Linlin Zhao; linlinsuc@sina.com
}

Received 23 May 2019; Revised 14 January 2020; Accepted 5 March 2020; Published 30 April 2020

Academic Editor: Sylwester Samborski

Copyright (c) 2020 Linlin Zhao et al. This is an open access article distributed under the Creative Commons Attribution License, which permits unrestricted use, distribution, and reproduction in any medium, provided the original work is properly cited.

Construction projects are typically conducted in a complex and dynamic environment in which the accumulation of many interrelated factors causes high uncertainty. Many factors may have negative effects on construction projects and thus cause project cost overruns. The aim of this study is to identify significant cost-influencing factors for sustainable development in construction. Considering the effects of economic and environmental factors on project cost is indeed a challenging task due to the shortage of appropriate methodology. This study examines the relationships between cost-influencing factors and construction project cost by using a structural equation model based on the generalized maximum entropy (GME) and Bayesian estimation methods. The advantages of GME and Bayesian methods are discussed, and results obtained from the statistical analysis are provided for illustration. The results can enhance cost performance through the identification and evaluation of the costinfluencing factors. The improved project performance is considered as an important step to transit into a sustainable development in construction. The sustainable development may greatly affect the emission reduction target of the industry.

\section{Introduction}

Construction projects typically operate in a complex and dynamic environment in which the accumulation of many interrelated factors causes high uncertainty [1-3]. Because of the uniqueness and complicatedness of construction projects, they can be subject to massive unexpected events. The inherent complexities and uncertainties of construction projects are due to the involvement of many parties, as well as political, economic, and social conditions under which the projects operate [4]. Complicatedness and uncertainties may have negative effects on the project with respect to cost, time, quality, safety, and sustainability $[5,6]$.

To improve project performance, it is imperative to establish a proper cost management strategy. Indeed, a comprehensive assessment of cost drivers form the foundation for developing realistic project cost management practices and strategies. Therefore, it is necessary to conduct a comprehensive and systematic examination of impacts of cost-influencing factors on the project. This process includes identifying, categorizing, and assessing multiple influencing factors related to construction project costs. Several studies have been conducted to identify and suggest categories for the influencing factors of project cost. However, previous studies pay little attention on the impacts of economic and environmental factors on project cost. During the last decade, construction projects in New Zealand have been impacted by many events, such as a wave of immigration, rapid economic development, the housing boom, and growth and expansion of the construction industry [7]. Hence, efforts should be made to identify and manage the cost-influencing factors of the New Zealand construction industry.

Certain advanced statistical techniques have also been introduced in construction studies and research. Structural equation modelling has become one of the most 
popular analysis methods in construction research over the last decade [8]. The widespread application of structural equation modelling stems from the fact that it is capable not only of exploring the relationships between measurement variables and latent variables but also the complex relationships among latent variables. Since it is difficult to directly observe variables, normal analysis techniques cannot be used for observation. SEM serves as a measurement model that can explore the relationship between latent constructs and corresponding measurement indicators and a structural model that reveals the relationship between latent constructs. SEM typically represents a covariance-based SEM that depends on the covariance matrix of the observed data [9]. In most cases, this approach can produce reliable results, but it is unable to produce accurate results when its assumptions cannot be met [10]. Importantly, the accuracy of the parameter estimates generated by a covariance-based SEM approach relies on a large sample size. Thus, use of a covariancebased SEM approach would encounter serious difficulties when using small sample sizes [11].

Therefore, this study attempts to introduce the structural equation modelling based on the generalized maximum entropy (GME) and Bayesian methods. The generalized maximum entropy (GME) method developed by [12] can be used as an alternative method to estimate parameters for structural equation modelling (SEM) [13]. The GME method is theoretical information-based, which aims to maximize the entropy function, and in turn, maximizes the missing information. The method reparameterizes and reformulates the structural models and estimates the parameters by using the maximum entropy method (MEM) developed by [14]. In fact, this method reparameterizes the unknown parameters and error terms into a convex combination and reformulates the origin model. The generalized maximum entropy (GME) is a flexible method where no model assumptions are necessary and global measure of model fit is provided. Recently, a Bayesian SEM has been found that can handle complex models and data structures. The statistical development in the Bayesian SEM relies on raw observation rather than the covariance matrix of the observed data. The Bayesian SEM uses genuine prior information and observed data to produce results and provides other useful statistics including the mean of the posterior distribution, and it works well with a small sample size. Hence, the Bayesian SEM has great potential in data analysis.

The rest of this paper is organized as follows. Section 2 presents a literature review about the cost-influencing factors and the gaps in existing literature. Section 3 describes the classification of the influencing factors and the hypothesis formation. Section 4 introduces the questionnaire survey, the generalized maximum entropy, and Bayesian estimation methods. Section 5 presents data analysis by using both estimation methods and provides model evaluation. The results are discussed in Section 6. Conclusions and implications are presented in Section 7.

\section{Literature Review}

2.1. Influencing Factors of Construction Project Cost. In [15], 55 factors were identified and seven were recognized as being the most significant drivers of cost, which included collaboration and communication among involved parties, competency of the project team, leading capability of clients, and the socioeconomic environment. In [16], a questionnaire survey and interview were conducted with construction professionals and described the ten most important influencing factors for construction projects, such as policy changes, market volatility, and bureaucratic organization structure. In [17], essential factors for projects in the USA were revealed, including regulation or code changes, contract conditions, financial failure, inflation, and weather.

In [18], a questionnaire survey was conducted on the largest Kuwaiti contractors, and the findings indicated that financial failure, contractual conditions, resources availability, collaboration and competence of the project team, political uncertainties, inflation, permits and regulations, weather conditions, and Acts of God were all significant factors. In [19], a questionnaire survey and case study were conducted on contractors in China and the results described a variety of influencing factors, such as regulation requirements, a client's objectives, competition, global trade influences, inefficient administration, the expertise of the project team, weather conditions, resources supply, and inflation.

In [20], interview surveys with project professionals were undertaken in India but were conducted by Singapore-based companies. The study results suggested that project financing and cultural differences were the main issues experienced by those construction projects. In [21], a questionnaire survey of construction professionals was performed in Australia and the results indicated that the factors that impact construction projects include excessive administration procedures and supply of resources. In [22], a fuzzy AHP method was performed and the results indicated that supply of resources, management cost, inflation, and complex organizational structures can significantly influence the project cost. In [23], the findings indicated that political factors are one of the most influential factors of construction projects because they are always related to the economy and investments, which severely impacts the exchange rate that, in turn, has a significant effect on imported goods. As described in [24], influence of stakeholders, regulatory requirements, external environment threats, and global influences impose increased pressure on project cost management.

2.2. Gaps in the Existing Literature. Several studies about factors impacting project cost in the context of construction have been performed. Although they have been conducted considering the factors that affect the project cost, a comprehensive study that includes all the significant influencing factors of project cost in New Zealand has rarely been 
performed. Moreover, factors influencing project cost in the construction industry are also viewed as a holistic entity. There is no study incorporating cost-influencing factors into a cohesive model. Therefore, developing a model that incorporates all the cost-influencing factors and project cost to examine their relationships is required. In addition, the study also introduces two alternative methods including the generalized maximum entropy and Bayesian methods, which can be used to estimate unknown parameters in structural equation modelling, and they are good at handling complex model with small sample size.

\section{Development of Variables and Hypotheses}

Grouping of the influencing factors is a part of factor identification; it tends to structure the diverse influencing factors that affect construction projects [21]. The current literature also suggests that the influencing factors should be categorized into groups [25]. According to the existing literature and the opinions of experts, the important cost drivers were identified and assessed that are divided into three main categories: construction project system, economic-market climate, and external environment.

3.1. Construction Project System. This type of influencing focuses on the project environment and refers to the influences imposed by the project context that directly impact the construction project cost. Construction project is usually conducted in a dynamic context, and the project can be affected by the context or the project system. In this study, the construction project system group includes cost-influencing factors such as resources supply and management $[26,27]$, competence and experience of key professionals $[28,29]$, relationship management and network development [30], organizational structure [31], risk management $[32,33]$, and contractual conditions $[34,35]$.

3.2. Economic-Market Climate. The construction projects are usually affected by the market change. Market condition is imperative for project success [36]. Economic stability can significantly influence the construction industry through employment and investments [37, 38]. Moreover, these factors also significantly affect the behavior of clients and construction companies. For example, reduced demand increases the competition between companies in the construction industry. As the construction industry usually relies on various financial resources to meet its capital needs, inherent financial constraints impose further influences on the overall project cost [39]. In this study, the economic-market climate category consists of the influencing factors such as market structure and size [40, 41], competition level [42], economic stability [37, 38], investment management [43], inflation target and interest management [44], credit supply conditions [39, 45], and exchange rate fluctuation [46].

3.3. External Environment. According to [47], global influences pose challenges to project cost performance, but industry professionals are less familiar with them. Political stability and financial influences play important roles in the broader economy in which construction projects operate; these are usually considered to be external influencing factors due to them being beyond the control of the stakeholders [48-50]. The construction industry is substantially affected by economic conditions [51]. It is important to understand that the global economy shapes many national economic activities. Furthermore, natural disasters also present many risks to the operational environment of a project. In this study, the external environment category comprised of influencing factors such as political stability [48-50], financial integration and deepening [52-54], global economic climate [51], and natural disasters $[55,56]$.

3.4. Hypotheses. While the definition of the project cost could differ from one organization to another, the most reliable and reasonable project cost definition lies in three dimensions: capital construction cost, associated capital cost, and client-related cost [57]. Using the categories of influencing factors and dimensions of the project cost, a hypothetical diagram of the research model is shown in Figure 1. The corresponding hypotheses are as follows:

Hypothesis 1: construction project system (CPS) has a significant effect on the construction project cost (CPC) in New Zealand

Hypothesis 2: economic-market climate (EMC) has a significant effect on the construction project cost (CPC) in New Zealand

Hypothesis 3: external environment (EE) has a significant effect on the construction project cost (CPC) in New Zealand

Hypothesis 4: economic-market climate (EMC) significantly influences construction project system (CPS) Hypothesis 5: external environment (EE) significantly influences economic-market climate (EMC)

Hypothesis 6: external environment (EE) significantly influences construction project system (CPS)

As addressed in [40], categorization of influencing factors is regarded to be highly subjective. Refinement of the correct measurement indicators to accurately represent the latent constructs is a complex task. It is difficult to represent or measure the latent construct with one observed variable. A comprehensive list of measurement indicators that clearly represents the corresponding latent constructs was developed, as shown in Table 1.

\section{Research Methodology}

The research methods used in this study are threefold: literature review, a pilot survey, and a questionnaire survey. A questionnaire survey was developed that requests the respondents to rate the influencing level of the measurement indicators using a five-point Likert scale ( $1=$ very weak, $2=$ weak, $3=$ medium, $4=$ strong, and $5=$ very strong). A five-point response format is desirable because it is sensitive 


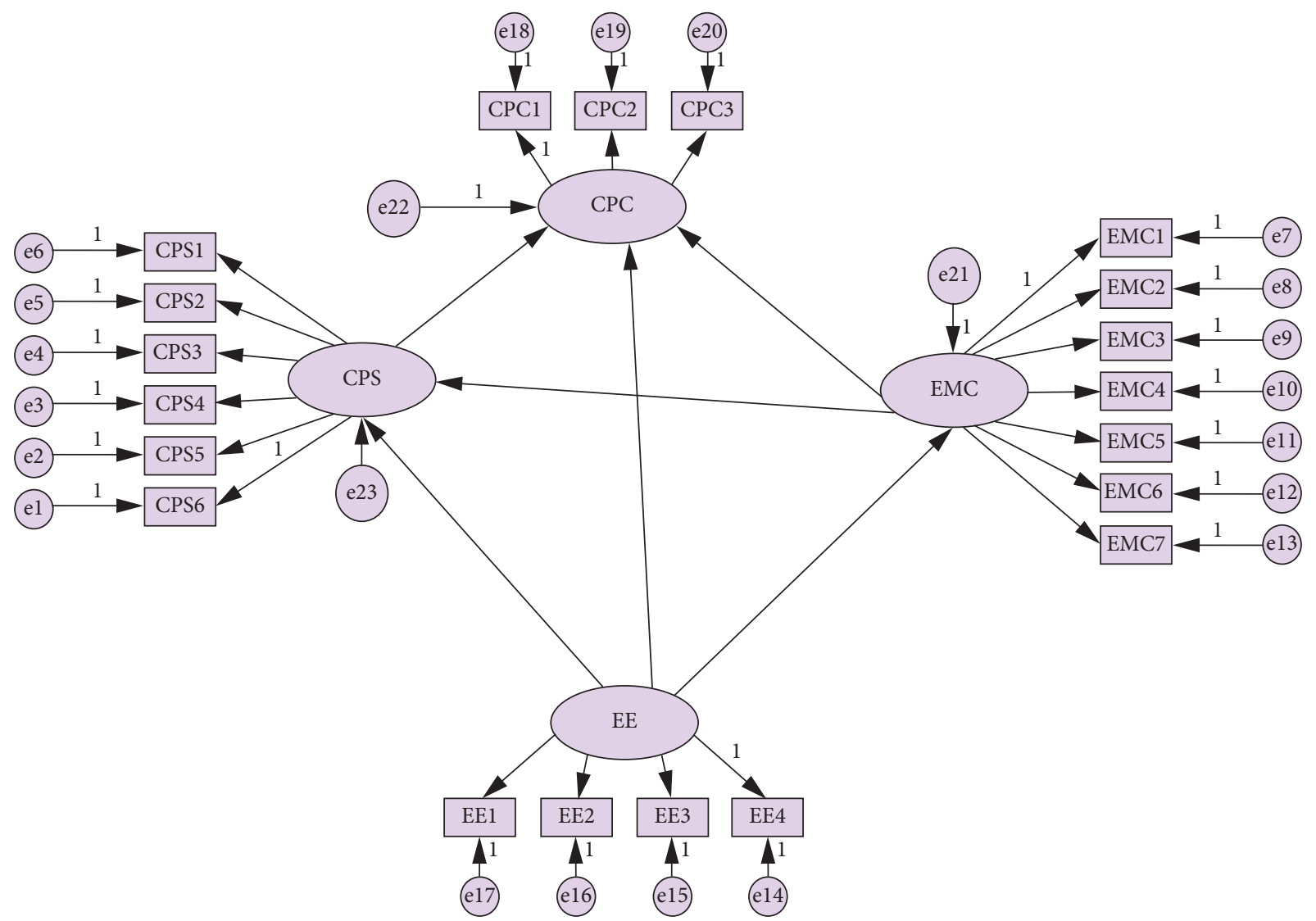

Figure 1: The proposed research model.

TABLE 1: Latent constructs and corresponding measurement indicators.

\begin{tabular}{|c|c|c|}
\hline Constructs & Factors & Sources \\
\hline Construction project system (CPS) & $\begin{array}{c}\text { Resource supply and management (CPS1) } \\
\text { Competence and experience of key professionals (CPS2) } \\
\text { Relationship management and network development (CPS3) } \\
\text { Organizational structure (CPS4) } \\
\text { Risk management (CPS5) } \\
\text { Contractual conditions (CPS6) }\end{array}$ & $\begin{array}{c}{[26,27]} \\
{[28,29]} \\
{[30]} \\
{[31]} \\
{[32,33]} \\
{[34,35]}\end{array}$ \\
\hline Economic-market climate (EMC) & $\begin{array}{c}\text { Market structure and size (EMC1) } \\
\text { Competition level (EMC2) } \\
\text { Economic stability (EMC3) } \\
\text { Investment management (EMC4) } \\
\text { Inflation target and interest management (EMC5) } \\
\text { Credit supply conditions (EMC6) } \\
\text { Exchange rate fluctuation (EMC7) }\end{array}$ & $\begin{array}{c}{[41,43]} \\
{[42]} \\
{[37,38,45]} \\
{[46,52]} \\
{[44]} \\
{[39,53]} \\
{[54]}\end{array}$ \\
\hline External environment (EE) & $\begin{array}{c}\text { Political stability (EE1) } \\
\text { Financial integration and deepening (EE2) } \\
\text { Global economic climate (EE3) } \\
\text { Natural disasters (EE4) }\end{array}$ & $\begin{array}{c}{[45,48-50]} \\
{[55,56,58]} \\
{[51]} \\
{[59,60]}\end{array}$ \\
\hline Construction project cost (CPC) & $\begin{array}{l}\text { Capital construction cost }(\mathrm{CPC} 1) \\
\text { Associated capital cost }(\mathrm{CPC} 2) \\
\text { Client-related cost }(\mathrm{CPC} 3)\end{array}$ & {$[57]$} \\
\hline
\end{tabular}

enough to differentiate the responses and it satisfies reliability and validity requirements [61].

Prior to formal distribution of the questionnaire survey, a pilot survey was carried out. Some questions were refined, rephrased, and reworded for better understanding. The target population for this study are registered members of the Association of Consulting Engineers of New Zealand (ACENZ), New Zealand Institution of Architects (NZIA), 
and New Zealand Institute of Quantity Surveyors (NZIQS). The professional backgrounds of the respondents encompass work experience, type of profession, and occupation.

4.1. Questionnaire Response. Of the 329 questionnaires that were distributed, 78 were completed and considered to be useful. Hence, the questionnaire response rate was 23.7 percent, which is reasonable based on previous similar studies and research [62-65]. Of the respondents, 13 percent had 6-10 years of work experience, 31 percent had 11-15 years of work experience, 27 percent had 16-20 years of work experience, 19 percent had 21-25 years of work experience, and 10 percent had more than 25 years of work experience. Of the 78 responding practitioners, 20 are architects, 18 are structural engineers, 12 are service engineers, 26 are quantity surveyors, and two are project managers. Background information of the respondents is shown in Table 2.

4.2. The Generalized Maximum Entropy Estimation Method. Since the development of the entropy theory by Shannon [66] and the principle of the maximum entropy theory introduced by Jaynes [67], the application of entropy has been widely used in many fields including social systems [68-70] and economic and financial sectors [71]. The entropy theory can be used to express uncertainty related to a probability distribution [72]. Considering a set of $n$ events, $\left\{E_{1}, E_{2}, \ldots, E_{n}\right\}$, uncertainty is defined as a situation, where no one knows which event will occur among the events. For the set of events $\left\{E_{1}, E_{2}, \ldots, E_{n}\right\}$, their respective probabilities can be expressed as $\left\{p_{1}, p_{2}, \ldots, p_{n}\right\}$, where $\sum p_{i}=1$. The entropy can reasonably measure the uncertainty associated with the events as

$$
\mathrm{H}=-\sum p_{i} \log _{2} p_{i}
$$

$\mathrm{H}(p)$ is the Shannon entropy used to measure the amount of uncertainty represented by $\left\{p_{1}, p_{2}, \ldots, p_{n}\right\}$.

The maximum entropy method (MEM) was first introduced by Jaynes [14, 67]. The generalized maximum entropy (GME) that is based on the classic maximum entropy method of Jaynes was first introduced by Golan et al. [12]. The advantages of the generalized maximum entropy (GME) method includes (1) not needing error assumptions and (2) can be used on small samples, and the covariates are highly correlated.

4.2.1. The Steps for the Application of GME Method. Based on the model and assumptions, the steps for the implementation of the GME estimation method includes reparametrization and reformulation.

Reparametrization: unknown parameters and disturbance terms are reparameterized as a convex combination of a district random variable

Reformulation: reformulate the model, and the reparametrization serves as the data constraint
GME method estimates unknown probabilities and assumes their sum is equal tol. In order to use the GME to estimate the unknown parameters of a structural model, the model requires reparametrization. Taking a simple linear model into account with $p$ observation and $q$ explanatory variables, the model can be written as

$$
y_{(p, 1)}=x_{(p, q)} \beta_{(q, 1)}+\varepsilon_{(p, 1)} .
$$

The model parameters and error terms are required to reparametrize to establish a convex combination of the expected value of a discrete random variable. Given equation (2), the model can be reformulated as

$$
y_{(p, 1)}=x_{(p, q)} Z_{(q, q, M)} p_{(q, M, 1)}+V_{(p, p, N)} \omega_{(p, N, 1)} .
$$

The diagonal matrices $Z$ and $V$ can be expressed as

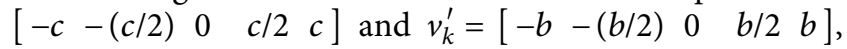
respectively, with $M=N=5$. The values in the matrices such as $b$ and $c$ are symmetrically chosen around zero with equally spaced distance.

The associated vectors $p_{(p, M, 1)}$ and $\omega_{(q, N, 1)}$ are the probabilities that have to be estimated using the GME. Then, the GME model can be expressed as

$\mathrm{H}(\mathrm{p}, \omega)=-p_{1, q, M}^{\prime} \ln p_{q, M, 1}-\omega_{1, p, N}^{\prime} \ln \omega_{p, N, 1}$.

The normalized consistency constraints can be expressed in equations (5) and (6):

$$
\begin{aligned}
& \left(I_{q, q} \bullet 1_{1, M}^{\prime}\right) p_{q, M, 1}=1_{q, 1}, \\
& \left(I_{p, p} \bullet 1_{1, N}^{\prime}\right) p_{p, M, 1}=1_{p, 1} .
\end{aligned}
$$

$I$ is the identity matrix, and 1 is a vector of one. These constraints should meet the following conditions: $\sum p_{i j}=1$ $(i=1, \ldots, q ; j=1, \ldots, M)$ and $\sum \omega_{h j}=1(h=1, \ldots, q ; j=1$, $\ldots, N)$.

4.2.2. The Application of GME on Structural Equation Modelling (SEM). The structural equation modelling can be expressed in equations (7)-(9):

$$
\begin{aligned}
& \eta_{(n, 1)}=B_{(n, n)} \eta_{(n, 1)}+\Gamma_{(n, m)} \xi_{(m, 1)}+\tau_{(n, 1)}, \\
& y_{(q, 1)}=\Lambda_{(q, n)}^{y} \eta_{(n, 1)}+\varepsilon_{(q, 1)}, \\
& x_{(p, 1)}=\Lambda_{(p, m)}^{x} \xi_{(m, 1)}+\delta_{(p, 1)} .
\end{aligned}
$$

Here, $\eta_{(n, 1)}$ is the vector of the $n$ endogenous latent variables, $\xi_{(m, 1)}$ is the vector of the $m$ exogenous latent variables, $y_{(q, 1)}$ is the vector of the $q$ endogenous measurement variables, $x_{(p, 1)}$ is the vector of the $p$ exogenous measurement variables, $B_{(n, n)}$ represents the interactions between endogenous variables, $\Gamma_{(n, m)}$ is a direct randomeffect matrix to express the effects of the exogenous variables on the endogenous variables, $\Lambda_{(q, n)}^{y}$ is the coefficient matrix to express the relationships between the endogenous latent variables and the measurement variables, $\Lambda_{(p, m)}^{x}$ is the coefficient matrix to express the relationships between the exogenous latent variables and the measurement variables, 
TABLE 2: A summary of respondents' profiles.

\begin{tabular}{lcccc}
\hline Profession & No. & Experience & Percent (\%) & Organization \\
\hline Architect & 20 & $6-10$ & 13 & Consultancy \\
Structural engineer & 18 & $11-15$ & 31 & Contractors \\
Service engineer & 12 & $16-20$ & 27 & Construction \\
Quantity surveyor & 26 & $21-25$ & 19 & Other \\
Project manager & 2 & $>25$ & 10 & 33 \\
\hline
\end{tabular}

$\tau_{(n, 1)}$ is the structural error vector, and $\varepsilon_{(q, 1)}$ and $\delta_{(p, 1)}$ are the measurement errors vectors. To properly express structural models, other matrices need to be defined. $\Phi$ is the covariance between latent variables, and $\Psi, \Theta^{\varepsilon}$, and $\Theta^{\delta}$ are the covariance matrices between the error terms $\tau, \varepsilon$, and $\delta$, respectively.

To apply the GME to structural equation modelling, follow the above presented steps. Initially, the above three structural models should be formed into one equation:

$$
\begin{aligned}
Y_{(p, 1)}= & \Lambda_{(p, m)}^{y}\left(I_{(m, m)}-B_{(m, m)}\right)^{-1}\left\{\Gamma_{(m, n)} \Lambda_{(n, q)}^{x-1}\left(X_{(q, 1)}-\delta_{(q, 1)}\right)\right. \\
& \left.+\tau_{(m, 1)}\right\}+\varepsilon_{(p, 1)},
\end{aligned}
$$

where $I_{(m, m)}$ is the identity matrix and $\Lambda_{(n, q)}^{x-1}$ is the general inverse of $\Lambda_{(n, q)}^{x}$. As MEM expert at estimate unknown probabilities. All the unknown parameters and error terms in the structural model should be reparameterized in the form of probabilities. Therefore, the coefficient matrices $B_{(m, m)}, \Gamma_{(m, n)}, \Lambda_{(p, m)}^{y}$, and $\Lambda_{(n, q)}^{x}$ and the covariance matrices, $\Phi, \Psi, \Theta^{\varepsilon}$, and $\Theta^{\delta}$ are all reparameterized, as shown in equation (11)-(17):

$$
\begin{gathered}
B_{(m, m)}=Z_{(m, m, M)}^{B} P_{(m, M, m)}^{B}, \\
\Gamma_{(m, n)}=Z_{(m, m, M)}^{\Gamma} P_{(m, M, n)}^{\Gamma}, \\
\Lambda_{(p, m)}^{y}=Z_{(p, p, M)}^{\Lambda^{y}} P_{(p, M, m)}^{\Lambda^{y}}, \\
\Lambda_{(q, n)}^{x}=Z_{(q, q, M)}^{\Lambda^{x}} P_{(q, M, n)}^{\Lambda^{x}}, \\
\tau_{(m, 1)}=V_{(m, m, N)}^{\tau} \omega_{(m, N, 1)}^{\tau}, \\
\mathcal{E}_{(p, 1)}=V_{(p, p, N)}^{\varepsilon} \omega_{(p, N, 1)}^{\varepsilon}, \\
\delta_{(q, 1)}^{\varepsilon}=V_{(q, q, N)}^{\delta} \omega_{(q, N, 1)}^{\delta} .
\end{gathered}
$$

Matrices $Z$ and $V$ are diagonal, and the genetic $k$ th element is represented, respectively, by the vectors

$$
\begin{aligned}
z_{k}^{\prime} & =\left[\begin{array}{lllll}
-c & -\frac{c}{2} & 0 & \frac{c}{2} & c
\end{array}\right], \\
v_{k}^{\prime} & =\left[\begin{array}{lllll}
-b & -\frac{b}{2} & 0 & \frac{b}{2} & b
\end{array}\right] .
\end{aligned}
$$

Given the reparameterization, the GME model has been remodeled:

$$
\begin{aligned}
\mathrm{H} & \left(p^{B}, p^{\Gamma}, p^{\Lambda^{y}}, p^{\Lambda^{x}}, \omega^{\tau}, \omega^{\varepsilon}, \omega^{\delta}\right)=-p_{(1, m \cdot m \cdot M)}^{B^{\prime}} \ln p_{(m . m . M, 1)}^{B} \\
& -p_{(1, m . n . M)}^{\Gamma^{\prime}} \ln p_{(m . n . M, 1)}^{\Gamma}-p_{(1, p . m . M)}^{\Lambda^{y^{\prime}}} \ln p_{(p . m . M, 1)}^{\Lambda^{y}} \\
& -p_{(1, q . n . M)}^{\Lambda^{x^{\prime}}} \ln p_{(q . n . M, 1)}^{\Lambda^{x}}+\omega_{(1, m . N)}^{\tau^{\prime}} \ln \omega_{(m . N, 1)}^{\tau} \\
& -\omega_{(1, p . N)}^{\varepsilon^{\prime}} \ln \omega_{(p . N, 1)}^{\varepsilon}-\omega_{(1, q . N)}^{\delta^{\prime}} \ln \omega_{(q . N, 1)}^{\delta}
\end{aligned}
$$

Subject to normalized constraints,

$$
\begin{gathered}
{\left[I_{(m, m)} \bullet 1_{(1, M)}\right] P_{(m . M, m)}^{B}=1_{(m, m)},} \\
{\left[I_{(m, m)} \bullet 1_{(1, M)}\right] P_{(m . M, n)}^{B}=1_{(m, n)},} \\
{\left[I_{(p, p)} \bullet 1_{(1, M)}\right] P_{(p . M, m)}^{\Lambda^{y}}=1_{(p, m)},} \\
{\left[I_{(q, q)} \bullet 1_{(1, M)}\right] P_{(q . M, n)}^{\Lambda^{x}}=1_{(q, n)},} \\
{\left[I_{(m, m)} \bullet 1_{(1, N)}\right] \omega_{(m \cdot N, 1)}^{\tau}=1_{(m, 1)},} \\
{\left[I_{(p, p)} \bullet 1_{(1, N)}\right] \omega_{(p \cdot N, 1)}^{\varepsilon}=1_{(p, 1)},} \\
{\left[I_{(q, q)} \bullet 1_{(1, N)}\right] \omega_{(q . N, 1)}^{\delta}=1_{(q, 1)} .}
\end{gathered}
$$

\subsection{Bayesian Structural Equation Modelling (SEM)}

4.3.1. Bayes' Theorem. Bayes' theorem of the Bayesian approach addresses that the probability of an event A conditional on an event $B$ equals the product of the probability that $B$ has occurred given $A$, and the probability of A divided by the probability that event B occurs [73]. This can be expressed as

$$
\mathrm{P}(A \mid B)=\frac{P(A \cap B)}{P(B)}=\frac{(P(B \mid A) P(A))}{P(B)} .
$$

If the events $A$ and $B$ are replaced with parameter $\theta$ and observed data $y$ and probabilities were replaced with a probability density function $(\mathrm{p}())$, then equation (4) can be rewritten as

$$
\mathrm{p}(\theta \mid y)=p(\theta \cap y) / p(y)=(p(y \mid \theta) p(\theta)) / p(y),
$$

where $p(\theta)$ is the prior probability density function; $p(y \mid \theta)$ is a likelihood function; and $\mathrm{p}(\theta \mid y)$ is the poster probability density function. As $p(y)$ does not depend on $\theta$, the abovementioned equation (5) can be expressed as

$$
\mathrm{p}(\theta \mid y)=p(\theta \cap y) / p(y) \propto(p(y \mid \theta) p(\theta)) .
$$

This can be considered as follows: 
Posterior probability density of the parameter$s \propto$ Likelihood function $\times$ Prior density.

The prior information about the parameter $\theta$ can be included into the Bayesian method through the prior distribution of $\theta$ in order to produce more accurate results. In fact, there are two types of prior distribution: noninformative prior distributions and informative prior distributions. The study used the results from covariance-based structural equation modelling. The means of the loadings obtained from the covariance-based SEM were used as the means of normal prior probability distributions for the loadings. To apply the Bayesian approach estimating structural equation modelling (SEM), the posterior distributions of parameters can be obtained from the corresponding sample means of posterior distribution. The means of the posterior distribution can be estimated from the simulated observations.

\subsubsection{The Difference between Covariance SEM and Bayesian} SEM. SEM is usually considered to be a regression model with latent and observed variables [74]. However, many studies using SEM were based on the covariance structure method, which usually has issues such as handling complex models, data patterns, and small samples. In contrast, a Bayesian SEM has advantages in coping with these problems.

The covariance-based SEM emphasizes fitting the covariance structure of the proposed model to the sample covariance matrix based on observed data. The parameter estimates in SEM depend on matrix variance covariance that is significantly based on the asymptotic normality of the sample. It works fine with a reasonably large sample and can provide good results when the data is normally distributed. However, it may come to difficulty when dealing with a complex model and data structure. Evaluating a small sample size in SEM using a common method such as Maximum Likelihood Estimation (ML) or Generalized Least Squares (GLS) can produce a negative variance and singular covariance matrix, which generates biased parameter estimates [75]. SEM has a limited ability to account for crossloading and residual correlation as they are fixed to zero, while Bayesian SEM can resolve this issue [76].

Bayesian SEM tends to allow for model development to be performed even if some essential assumptions are not fulfilled. Bayesian SEM depends on the number of observations [77]. In covariance SEM, the estimated parameter is not considered as a random variable, while in Bayesian SEM it is considered to be a random variable that has a distribution termed prior distribution. The prior information, Bayes' theorem, and posterior are introduced into Bayesian SEM, which is better at describing the distribution of data than asymptotic approximation because the finite-sample distribution of data is unknown. The prior information is indeed a distinguishing advantage that quantifies prior uncertainty in the analysis. Additionally, the Bayesian SEM can incorporate the prior information into the estimate. As for the added information provided by the data, more accurate and reliable parameter estimates can be obtained. Moreover, the uncertainty from the stochastic nature of the data is also considered by Bayesian SEM. By combining the random effects and the prior information, Bayes' theorem transforms prior information into posterior. In addition, the Markov Chain Monte Carlo used in Bayesian SEM can perform unlimited iteration while the maximum likelihood estimation in covariance-based SEM can only set a maximum number of iterations, such as 500. If the limit is exceeded, the maximum likelihood estimates fail to converge.

Although pure indicators for only one construct may exist, most indicators have a certain level of association with other constructs [78]. Excluding crossloading in an analysis would cause inflated construct correlations [79]. This point is also confirmed by [78], which states that construct correlations appear to be upwardly biased if the crossloadings are constrained to be zero. Even when the model ignores small and meaningless crossloadings, the construct correlations tend to be substantially biased. Moreover, Bayesian SEM can identify the residual correlation, which is the main cause of misfit in the SEM model and inaccurate parameter estimates [80]. Sometimes, misfit in the SEM model may be due to the ignorance of the residual correlations rather than a major difference between the model and data.

\section{Data Analysis}

In this study, SEM, a multivariate analysis technique, was used to test the proposed research model. SEM is a promising research tool for the following reasons. First, SEM is widely accepted as a reliable approach for hypothesis testing [81]. Second, as a multivariate analysis, SEM is allowed to analyze multiple relationships simultaneously [74]. Finally, SEM can examine the causal relationship between latent variables [82]. Moreover, SEM based on generalized maximum entropy (GME) and Bayesian methods were adopted in this study, instead of the Maximum Likelihood Estimation and Generalized Least Squares (GLS) commonly used in covariance-based SEM.

5.1. SEM-GME. In the defined structural model shown in Figure 1, the endogenous latent variable is the construction project cost (CPC) and the exogenous latent variables include the construction project system (CPS), economicmarket climate (EMC), and external environment (EE). The structural model defines the linear relationships among the latent variables, and the relationships between the latent variables and their measurement variables. The structural model can be expressed in equations (24)-(26):

$$
\begin{aligned}
\eta_{(1,1)} & =\mathrm{B}_{(1,1)} \eta_{(1,1)}+\Gamma_{(1,3)} \xi_{(3,1)}+\tau_{(1,1)}, \\
\mathrm{y}_{(3,1)} & =\Lambda_{(3,1)}^{\mathrm{y}} \eta_{(1,1)}+\varepsilon_{(3,1)}, \\
\mathrm{x}_{(17,1)} & =\Lambda_{(17,1)}^{\mathrm{x}} \xi_{(3,1)}+\delta_{(17,1)} .
\end{aligned}
$$

The covariance matrices include $\Phi_{(3,3)}$ of the latent exogenous variables, $\Psi_{(1,1)}$ of the error term $\tau, \Theta_{(3,3)}^{\varepsilon}$ of the error term $\varepsilon$, and $\Theta_{(17,17)}^{\delta}$ of the error term $\delta$. 
Given the abovementioned model, the generalized maximum entropy (GME) method was performed to obtain the unknown parameters and error terms. Following the above stated steps, the models should be united to one and reparameterize. Then, the structural equations (24)-(26) can be written in one model:

$$
\begin{aligned}
y_{(3,1)}= & \Lambda_{(3,1)}^{y}\left(I_{(1,1)}-B_{(1,1)}\right)^{-1}\left\{\Gamma_{(3,3)}\left(\Lambda^{x}\right)_{(3,17)}^{-1}\left(x_{(17,1)}-\delta_{(17,1)}\right)\right. \\
& \left.+\tau_{(1,1)}\right\}+\varepsilon_{(3,1)} .
\end{aligned}
$$

The GME method is good at handling unknown probabilities; however, the unknown parameters in the defined structural model are not in the form of probabilities, and their sum does not indicate unity. Therefore, in order to obtain the estimated unknown parameters using the GME, the unknowns should be rewritten in the form of probability values. At this stage, the coefficients and error terms should be reparameterized with $M$ and $N$ fixed points (FPs).

$\Lambda_{(3,1)}^{y}$ is an example for illustrating the reparameterized model

$$
\Lambda_{(3,1)}^{y}=\left[\begin{array}{l}
\lambda_{1}^{y} \\
\lambda_{2}^{y} \\
\lambda_{3}^{y}
\end{array}\right]=Z_{(3,3 . M)}^{\Lambda^{y}} p_{(3 . M, 1)}^{\Lambda^{y}}=\left[\begin{array}{lll}
z_{1} & & \\
& z_{2} & \\
& & z_{3}
\end{array}\right]\left[\begin{array}{c}
p_{1}^{\Lambda^{y}} \\
p_{2}^{\Lambda^{y}} \\
p_{3}^{\Lambda^{y}}
\end{array}\right],
$$

with the normalized constraint for $p_{(3, M, 1)}^{\Lambda^{y}}$ :

$$
\left[\mathrm{I}_{(3,3)} \bullet 1_{(1, \mathrm{M})}\right] \bullet \mathrm{p}_{(3, \mathrm{M}, 1)}^{\Lambda^{\mathrm{y}}}=1_{(3,1)} \text {. }
$$

In a similar transformation, the other parameters can also be reparameterized.

After reparameterization, the structural model can be reformed. The original structural model (27) was substituted by the formula in which all the unknown parameters and error terms are represented in the form of probabilities:

$$
\begin{aligned}
\mathrm{y}_{(3,1)}= & ?\left(\mathrm{p}^{\mathrm{B}}, \mathrm{p}^{\Gamma}, \mathrm{p}^{\Lambda^{\mathrm{y}}}, \mathrm{p}^{\Lambda^{\mathrm{x}}}, \omega^{\tau}, \omega^{\varepsilon}, \omega^{\delta}\right) \\
= & \left(\mathrm{Z}_{(3,3 . \mathrm{M})}^{\Lambda^{\mathrm{y}}} \mathrm{p}_{(3 . \mathrm{M}, 1)}^{\Lambda^{\mathrm{y}}}\right)\left[\mathrm{I}_{(1,1)}-\left(\mathrm{Z}_{(1,1 . \mathrm{M})}^{\mathrm{B}} \mathrm{p}_{(1 . \mathrm{M}, 1)}^{\mathrm{B}}\right)\right]^{-1} \\
& \left\{\left(\mathrm{Z}_{(1,3 . \mathrm{M})}^{\Gamma} \mathrm{p}_{(3 . \mathrm{M}, 3)}^{\Gamma}\right)\left(\mathrm{Z}_{(17,17 . \mathrm{M})}^{\Lambda^{\mathrm{x}}} \mathrm{p}_{(17 . \mathrm{M}, 1)}^{\Lambda^{\mathrm{x}}}\right)^{-1}\right. \\
& {\left.\left[\mathrm{x}_{(17,1)}-\left(\mathrm{V}_{17,17 . \mathrm{N}}^{\delta} \omega_{(17 . \mathrm{N}, 1)}^{\delta}\right)\right]+\left(\mathrm{V}_{(1,1 . \mathrm{N})}^{\tau} \omega_{(1 . \mathrm{N}, 1)}^{\tau}\right)\right\} } \\
& +\left(\mathrm{V}_{(3,3 . \mathrm{N})}^{\varepsilon} \omega_{(3 . \mathrm{N}, 1)}^{\varepsilon}\right) .
\end{aligned}
$$

The model has been reformed. With the principle of the generalized maximum entropy (GME) method, the objective function shown in (31) should be maximized:

$$
\begin{aligned}
& \mathrm{H}\left(\mathrm{p}^{\mathrm{B}}, \mathrm{p}^{\Gamma}, \mathrm{p}^{\Lambda^{y}}, \mathrm{p}^{\Lambda^{x}}, \omega^{\tau}, \omega^{\varepsilon}, \omega^{\delta}\right) \\
& =-\mathrm{p}_{(1,1, \mathrm{M})}^{\mathrm{p}^{\prime}} \ln \mathrm{p}_{(1 . \mathrm{M}, 1)}^{\mathrm{B}}-\mathrm{p}_{(1,3 . \mathrm{M})}^{\mathrm{r}^{\prime}} \ln \mathrm{p}_{(3 . \mathrm{M}, 1)}^{\mathrm{\Gamma}}-\mathrm{p}_{(1,3 . \mathrm{M})}^{\Lambda^{y^{\prime}}} \ln \mathrm{p}_{(3 . \mathrm{M}, 1)}^{\Lambda^{y}} \\
& -\mathrm{p}_{(1,51 . \mathrm{M})}^{\Lambda^{x}} \ln \mathrm{p}_{(51 . \mathrm{M}, 1)}^{\Lambda^{\mathrm{x}}}+\omega_{(1,1, \mathrm{~N})}^{\tau} \ln \omega_{(1 . \mathrm{N}, 1)}^{\tau}-\omega_{(1,3 . \mathrm{N})}^{\varepsilon^{\prime}} \ln \omega_{(3 . \mathrm{N}, 1)}^{\varepsilon} \\
& -\omega_{(1,17 . \mathrm{N})}^{\delta} \ln \omega_{(17 . \mathrm{N}, 1)}^{\delta} \text {. }
\end{aligned}
$$

Subject to normalized constraints,

$$
\begin{aligned}
{\left[\mathrm{I}_{(1,1)} \bullet 1_{(1, \mathrm{M})}\right] \mathrm{P}_{(1 . \mathrm{M}, 1)}^{\mathrm{B}} } & =1_{(1,1)}, \\
{\left[\mathrm{I}_{(1,1)} \bullet 1_{(1, \mathrm{M})}\right] \mathrm{P}_{(1 . \mathrm{M}, 3)}^{\mathrm{B}} } & =1_{(1,3)}, \\
{\left[\mathrm{I}_{(3,3)} \bullet 1_{(1, \mathrm{M})}\right] \mathrm{P}_{(3 . \mathrm{M}, 1)}^{\Lambda^{y}} } & =1_{(3,1)}, \\
{\left[\mathrm{I}_{(17,17)} \bullet 1_{(1, \mathrm{M})}\right] \mathrm{P}_{(17 . \mathrm{M}, 1)}^{\Lambda^{\mathrm{X}}} } & =1_{(17,1)}, \\
{\left[\mathrm{I}_{(1,1)} \bullet 1_{(1, \mathrm{~N})}\right] \omega_{(1 . \mathrm{N}, 1)}^{\tau} } & =1_{(1,1)}, \\
{\left[\mathrm{I}_{(3,3)} \bullet 1_{(1, \mathrm{~N})}\right] \omega_{(3 . \mathrm{N}, 1)}^{\varepsilon} } & =1_{(3,1)}, \\
{\left[\mathrm{I}_{(17,17)} \bullet 1_{(1, \mathrm{~N})}\right] \omega_{(17 . \mathrm{N}, 1)}^{\delta} } & =1_{(17,1)} .
\end{aligned}
$$

The estimation results are shown in Table 3. The path significance is based on the $p$ value of the path coefficient [83]. Therefore, the hypotheses $1,2,4$, and 5 is supported by the analysis results, as they have $p$ value less than 0.05 .

5.2. Bayesian SEM. The proposed research model can be examined by Bayesian SEM. In Bayesian SEM, all estimated coefficients are reported in terms of posterior distribution. In Bayesian inference, instead of parameter significance testing, plausible reasoning should be employed. Plausible reasoning attempts to validate or invalidate hypotheses using uncertain information and can be used to reason about the truth of single hypothesis ( $\mathrm{HO}$ or $\mathrm{H} 1$ ). In this study, hypotheses are used in the Bayesian SEM method:

$\mathrm{H} 0$ : the exogenous variable has no significant effect on the endogenous variable

$\mathrm{H} 1$ : the exogenous variable has a significant effect on the endogenous variable

The acceptance or rejection of based on the presence or absence of zero value in a credible interval on each parameter $[77,84]$. Parameter is said to be significant (reject $\mathrm{H} 0)$ ) if credible interval does not contain the zero value and means that the exogenous variable has a significant effect on the endogenous variable. Otherwise, a parameter is said to be nonsignificant (accept $\mathrm{HO}$ )) if credible interval includes zero value means that the exogenous variable has no significant influence on the endogenous variable.

The hypothesis testing can be conducted on both the measurement model and the structural model. In the measurement model, a significant indicator means it is acceptable to measure the corresponding latent construct. In the structural model, the hypothesis testing can determine whether there is a significant relationship between the latent constructs. The regression weights and the associated 95 percent confidence intervals between the measurement indicators and corresponding latent constructs and between the latent constructs are shown in Tables 4 and 5, respectively. Based on the results presented in Table 4, factor loadings are all significant at the 5 percent level, except the indicator exchange rate fluctuation (EMC7). Based on the results of the structural model shown in Table 5, of the six parameters tested, four parameters were recognized as being significant. These results support hypotheses $1,2,4$, and 5 but do not support hypotheses 3 and 6 . 
TABLE 3: SEM-GME results of hypotheses testing.

\begin{tabular}{|c|c|c|c|}
\hline Hypotheses & Path & GME(P) & $p$ value \\
\hline $\mathrm{H} 1$ & $\mathrm{CPC} \longleftarrow \mathrm{CPS}$ & 0.432 & 0.001 \\
\hline $\mathrm{H} 2$ & $\mathrm{CPC} \longleftarrow \mathrm{EMC}$ & 0.468 & 0.000 \\
\hline $\mathrm{H} 3$ & $\mathrm{CPC} \longleftarrow \mathrm{EE}$ & 0.083 & 0.781 \\
\hline $\mathrm{H} 4$ & $\mathrm{CPS} \longleftarrow \mathrm{EMC}$ & 0.208 & 0.013 \\
\hline H5 & $\mathrm{EMC} \longleftarrow \mathrm{EE}$ & 0.384 & 0.008 \\
\hline H6 & $\mathrm{CPS} \longleftarrow \mathrm{EE}$ & 0.009 & 0.259 \\
\hline
\end{tabular}

TABle 4: Bayesian SEM measurement model results.

\begin{tabular}{|c|c|c|c|c|}
\hline Path & Mean & $\mathrm{SD}$ & $95 \%$ lower bond & $95 \%$ upper bond \\
\hline CPS1 CPS & 0.933 & 0.061 & 0.820 & 1.062 \\
\hline $\mathrm{CPS} 2 \longleftarrow \mathrm{CPS}$ & 0.927 & 0.065 & 0.805 & 1.058 \\
\hline $\mathrm{CPS} 3 \longleftarrow \mathrm{CPS}$ & 0.914 & 0.064 & 0.795 & 1.044 \\
\hline $\mathrm{CPS} 4 \longleftarrow \mathrm{CPS}$ & 1.033 & 0.064 & 0.913 & 1.164 \\
\hline CPS $5 \longleftarrow$ CPS & 1.035 & 0.065 & 0.916 & 1.169 \\
\hline $\mathrm{EMC} 2 \longleftarrow \mathrm{EMC}$ & 0.983 & 0.057 & 0.876 & 1.100 \\
\hline $\mathrm{EMC} 3 \longleftarrow \mathrm{EMC}$ & 0.991 & 0.053 & 0.890 & 1.101 \\
\hline $\mathrm{EMC} 4 \longleftarrow \mathrm{EMC}$ & 0.989 & 0.054 & 0.887 & 1.099 \\
\hline EMC5 $\longleftarrow$ EMC & 0.979 & 0.056 & 0.874 & 1.094 \\
\hline EMC6 $\longleftarrow$ EMC & 0.985 & 0.058 & 0.877 & 1.104 \\
\hline EMC7 $\longleftarrow$ EMC & -0.17 & 0.084 & -0.338 & -0.008 \\
\hline $\mathrm{EE} 1 \longleftarrow \mathrm{EE}$ & 0.987 & 0.090 & 0.823 & 1.174 \\
\hline $\mathrm{EE} 2 \longleftarrow \mathrm{EE}$ & 1.030 & 0.090 & 0.865 & 1.219 \\
\hline $\mathrm{EE} 3 \longleftarrow \mathrm{EE}$ & 1.036 & 0.094 & 0.864 & 1.229 \\
\hline $\mathrm{CPC} 2 \longleftarrow \mathrm{CPC}$ & 0.933 & 0.106 & 0.740 & 1.153 \\
\hline $\mathrm{CPC} 3 \longleftarrow \mathrm{CPC}$ & 0.919 & 0.102 & 0.731 & 1.134 \\
\hline
\end{tabular}

TABLE 5: Bayesian SEM results of hypotheses testing.

\begin{tabular}{|c|c|c|c|c|c|}
\hline Hypotheses & Path & Mean & $\mathrm{SD}$ & 95\% lower bond & $95 \%$ upper bond \\
\hline $\mathrm{H} 1$ & $\mathrm{CPC} \longleftarrow \mathrm{CPS}$ & 0.819 & 0.079 & 0.675 & 0.986 \\
\hline $\mathrm{H} 2$ & $\mathrm{CPC} \longleftarrow \mathrm{EMC}$ & 0.792 & 0.065 & 0.67 & 0.925 \\
\hline H3 & $\mathrm{CPC} \longleftarrow \mathrm{EE}$ & 0.797 & 0.569 & -0.174 & 2.031 \\
\hline $\mathrm{H} 4$ & $\mathrm{CPS} \longleftarrow \mathrm{EMC}$ & 0.102 & 0.052 & 0.001 & 0.206 \\
\hline H5 & $\mathrm{EMC} \longleftarrow \mathrm{EE}$ & 0.583 & 0.075 & 0.328 & 0.779 \\
\hline H6 & $\mathrm{CPS} \longleftarrow \mathrm{EE}$ & 0.097 & 0.153 & -0.195 & 0.409 \\
\hline
\end{tabular}

Hypothesis 3, which states that the external environment has a significant effect on construction project cost, is not supported by the regression weight of EE on CPC, with a $95 \%$ probability interval from -0.174 to 2.031 . The relevant regression weight for hypothesis 6, i.e., the external environment has a significant effect on the construction project system and has a posterior $95 \%$ probability interval between -0.195 and 0.409 . Indicating that $\mathrm{H} 0$ was accepted in the two relationships, external environment (EE) has no significant effect on construction project cost (CPC) and construction project system (CPS). Therefore, hypotheses 3 and 6 are not supported.

For hypothesis 1, which states that the construction project system has a significant effect on the construction project cost, the confidence interval of the regression parameter ranges from 0.675 to 0.986 , which is significantly larger than zero. Hypothesis 2, which asserts that the economic-market climate has a significant effect on construction project cost, has a confidence interval between 0.670 and 0.925 and a parameter that is significantly greater than zero. Support was found for hypothesis 4 , stating that the economic-market climate can significantly affect a construction project system, with a confidence interval ranging from 0.001 to 0.206 . Finally, hypothesis 5 was supported, which stated that the external environment has a significant effect on the economic-market climate, with a confidence interval between 0.328 and 0.779 . Based on the previous statements, $\mathrm{H} 0$ was rejected in these four relationships. Thus, the hypotheses $1,2,4$, and 5 are supported.

\subsection{Model Assessment}

5.3.1. The Assessment of SEM-GME. Recently, the goodnessof-fit (GoF) index has been introduced to evaluate the model fitness, which serves as a geometric mean of the average $R^{2}$ 
value of each latent variable [85]. However, the GoF index is based on local measures, not on a global measure of model fit, as $R^{2}$ refers to the single latent variable. The GME estimation method provides a global measure of the goodness of the model by offering the measure of the normalized entropy index that quantifies the level of information in the data $[86,87]$. The normalized entropy index can be used to measure the reduction in uncertainty information and can be calculated as

$$
\mathrm{S}(\bar{p})=\frac{-p^{\prime} \ln p}{K \ln M},
$$

where $-p^{\prime} \ln p$ is the entropy function, as shown in equation (4); $K$ is the number of predictors; and $M$ is the number of fixed points (FPs).

Furthermore, a pseudo- $R^{2}$ can be expressed in equation (34). The value of $R^{2}$ can be used to evaluate the goodness of model fit, where the value 0 indicates no information value of the dataset, and 1 indicates prefect model fit:

$$
R^{2}=1-\mathrm{S}(\bar{p})
$$

The GME estimation method provides a global evaluation of the investigated problem by providing the normalized entropy index that measures the goodness of relationships based on the level of information explained by the model. The normalized entropy index and pseudo- $\mathrm{R}^{2}$ are reported in Table 6. $S(\bar{p})=0.17$ implies that the reduction in the uncertainty is about $80 \%$, which is a good result based on the suggestion of [86]. Additionally, the pseudo $-\mathrm{R}^{2}=0.83$ indicates a good model fit.

5.3.2. The Assessment of Bayesian SEM. Posterior predictive $p$-value is used to assess the research model, as it can account for both the fit between the research model and the observed data and the match between the replicated data and the observed data $[88,89]$. A poster predictive value close to 0.5 indicates a good fit. In this study, the posterior predictive $p$ value is 0.46 , indicating the model fits the data well.

Although Bayesian SEM has advantages over covariancebased SEM, convergence problems bias the result of Bayesian estimation [90]. Thus, a convergence check should be conducted in Bayesian SEM in order to obtain an adequate model. However, convergence checking is not a simple task in Markov Chain Monte Carlo (MCMC) estimation, as it is devised to converge in distribution rather than to a point estimate [91]. A single convergence test is not sufficient; it is common to graphically inspect several different aspects of convergence conditions, including time series plots and posterior density plots $[92,93]$. Typically, in a posterior trace plot, a parameter appears to converge when a tight horizontal band is formed from sample estimations. Otherwise, if a trace plot shows significant fluctuation, the parameter has most likely not reached convergence.

The convergence trace plot, as shown in Figure 2, has a tight band that lies within two parallel horizontal lines; no trend is observed that indicates that the parameters properly converged. As shown in trace plots in Figure 2, after several
TABle 6: Model fit comparison.

\begin{tabular}{lcccc}
\hline Model & \multicolumn{2}{c}{ Bayesian SEM } & \multicolumn{2}{c}{ SEM-GME } \\
& $\begin{array}{c}\text { Posterior } p \\
\text { value }\end{array}$ & DIC & $\begin{array}{c}\text { Entropy ratio } \\
\mathrm{S}(\bar{p})\end{array}$ & $\begin{array}{c}\text { Pseudo- } \\
\mathrm{R}^{2}\end{array}$ \\
\hline $\begin{array}{l}\text { First } \\
\text { model }\end{array}$ & 0.46 & 470.4 & 0.17 & 0.83 \\
$\begin{array}{l}\text { Final } \\
\text { model }\end{array}$ & 0.48 & 466.6 & 0.12 & 0.88 \\
\hline
\end{tabular}

thousand iterations, the sequences of the values generated at different starting points show good mixing.

If a polygon in posterior distribution formed a bell shape in approximately normal density, the parameter is properly converged [88]. A smoothed density for the posterior distribution of the variance of construction project cost is shown in Figure 3. The estimated value of the variance is 0.520 , which is close to 0.5 . According to [94], the estimated variance value of 0.5 indicates a perfect model fit, and significantly smaller or greater than 0.5 indicates a bad fit. This indicates that the variance of construction project cost is well accounted for by the proposed model. The variances of the remaining variables are similar to that in Figure 3, which indicates that the variances are well accounted for by the model.

5.4. Model Comparison. After statistical analysis, the insignificant paths are removed from the structural model to improve the fitness of the model. Thus, only the significant paths remains in the final model. To validate the final model is better than the first conceptual model, the normalized entropy index $S(\bar{p})$ and pseudo- $\mathrm{R}^{2}$ were calculated. The results are shown in Table 6 . The results indicate the final model is better than the first model as the final model has a higher value of pseudo- $\mathrm{R}^{2}$. The final model based on generalized maximum entropy method is shown in Figure 4 . The broken lines indicate the insignificant paths, while the solid lines indicate significant paths.

It is very common in SEM to compare a set of competing models and select the one that yields the best fit. Although Bayesian Information Criterion (BIC) is derived from Bayesian theory, it is frequently used to compare models in covariance-based SEM [95]. The Bayes factor is another statistic that can be used for comparing models, but it is sensitive to prior inputs [96]. Therefore, a notion of Bayesian deviance, Deviance Information Criterion (DIC), was introduced for comparing models in Bayesian SEM by [89]. Similar to the BIC, the model that has the smallest DIC from a set of comparative models is favorable. Based on previous results, the final model deletes the insignificant paths of the first model. The DIC results indicate that the final model has a better fit than the first model, as shown in Table 3. The final model is shown in Figure 5.

\section{Results and Discussion}

This study attempts to empirically examine the effects of construction project system, economic-market climate, and 


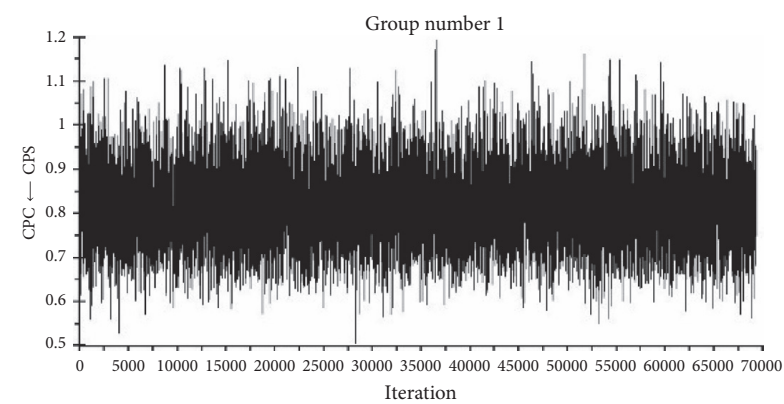

(a)

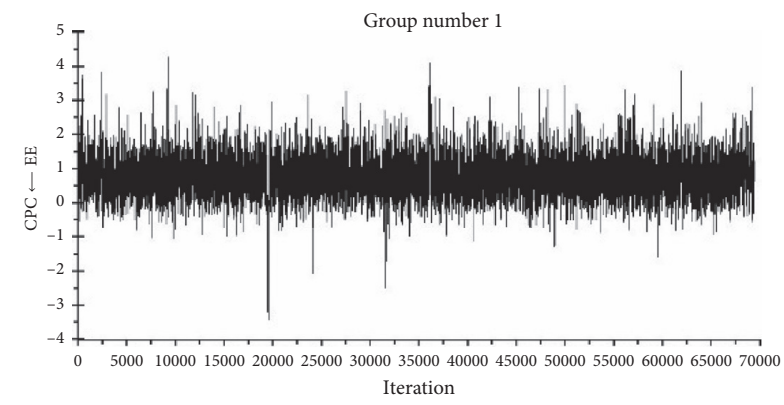

(c)

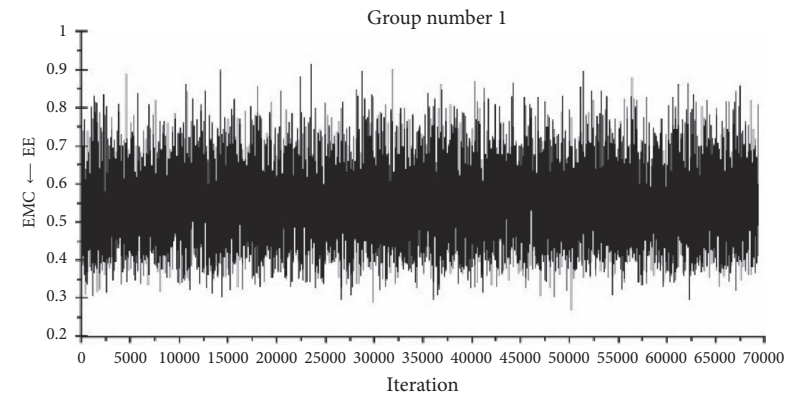

(e)

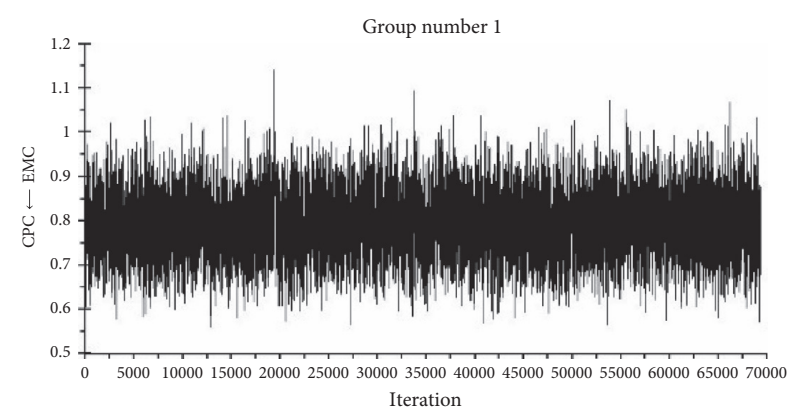

(b)

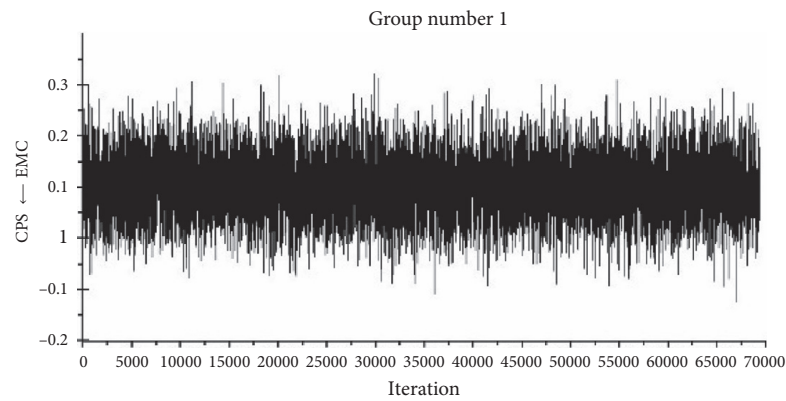

(d)

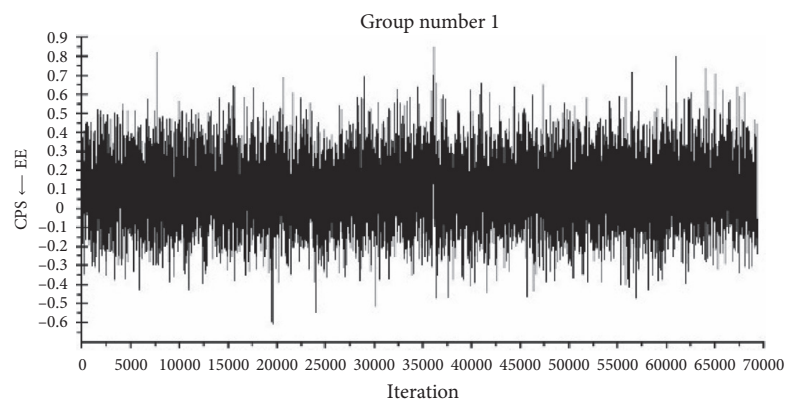

(f)

Figure 2: Trace plot convergence for model parameters.

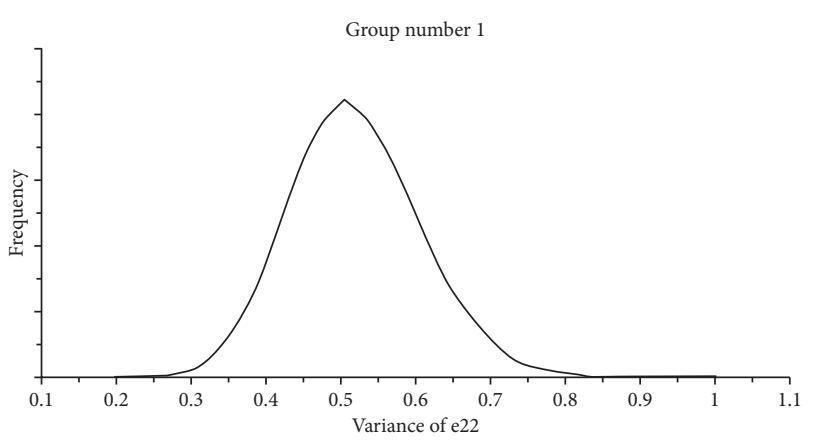

Figure 3: Posterior density of the model residue.

external environment on the cost of construction projects, the effects of external environment on construction project cost through economic-market climate and construction project system, and the effect of economic-market climate on the construction project system by using structural equation

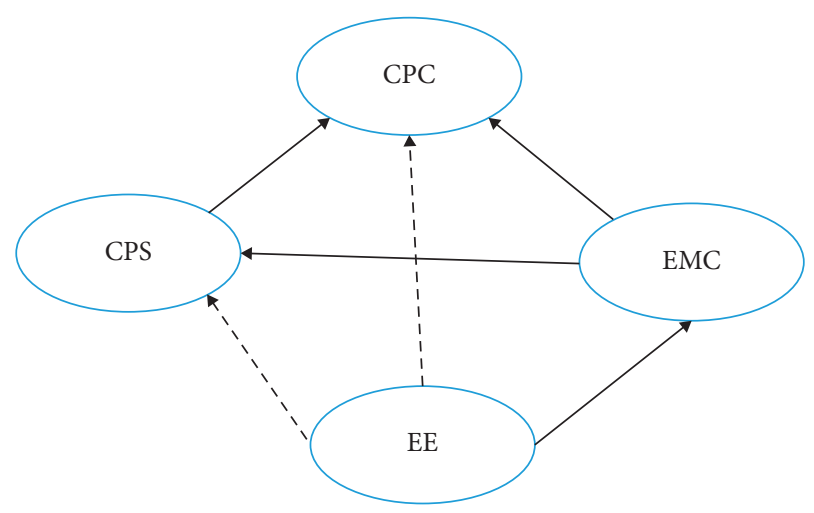

Figure 4: The final research model based on the generalized maximum entropy (MEP) method.

modelling based on the generalized maximum entropy and Bayesian methods. Research hypotheses are grounded in existing research findings and empirical results. 


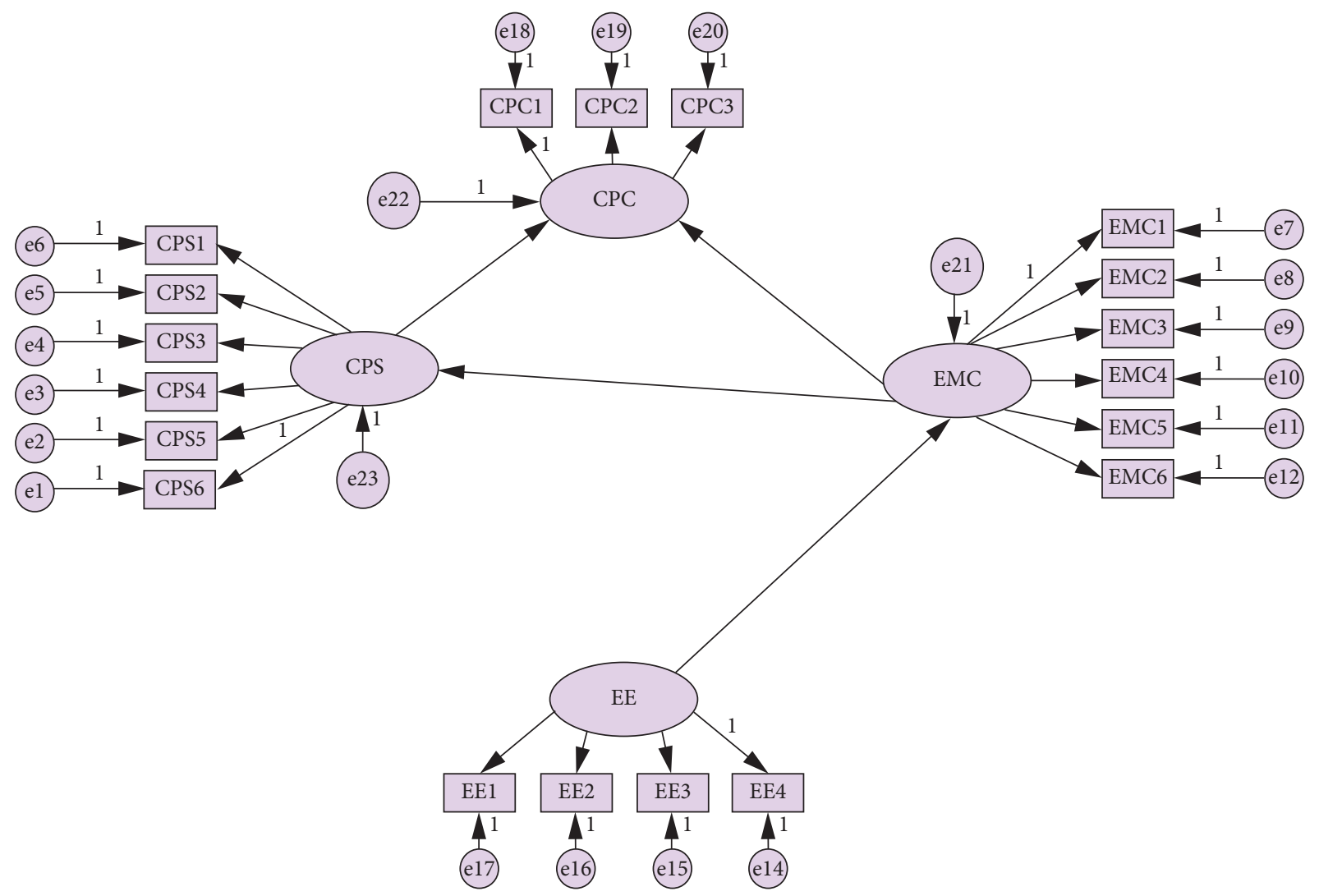

Figure 5: The final research model based on the Bayesian method.

Both the Bayesian and the maximum entropy methods were used to estimate the parameters of the construction cost structural model. The final structural model obtained based on the generalized maximum entropy (GME) method is shown in Figure 4 where only significant relationships are displayed. The results indicate that two of three exogenous latent variables-- the construction project system (CPS) and the economic-market climate (EMC) - have significant effects on construction project cost (CPC). They can directly influence CPC. This result is the same as that obtained from the Bayesian method.

The results explored that the construction project system has a significant effect on the construction project cost. This study also supports the findings of a previous study related to project cost management $[97,98]$. Moreover, the significant effect of economic-market climate on construction project cost was also confirmed. Essentially, this finding can be explained by the fact that capital is one of its most important factors because construction projects need a large amount of working capital to run daily construction activities. Since most contractors rely heavily on their financial sources, credit supply conditions can have a significant impact on their financial capacity. This explanation is also consistent with previous research $[99,100]$.

The results also revealed that the significant effect of economic-market climate on the construction project system is consistent with previous research findings [101, 102]. Based on this finding, this study suggests that construction professionals should facilitate appropriate resource management and risk management practices and strategies in order to better manage project costs. Additionally, the postulated relationship between external environment and economic-market climate was also validated. A possible explanation for this finding is that incorporation of natural disasters into the external economic construct increased the demand for construction products, as this sudden demand imposed a raft of challenges on construction resources.

However, the significant effect of external environment on the construction project cost has not been confirmed. This result contradicts previous research findings [103] that indicated that project operation environment has a significant effect on project success. In our opinion, this result may be caused by the data that were used. As the data were collected from consultants such as architects, engineers, and quantity surveyors, these professions may be more concerned with tangible factors such as construction resources rather than intangible factors such as global business sentiments.

Furthermore, the significant effect of external environment on construction project system was not supported by this study. This result is in contrast with previous research findings [104], which is likely due to this study only considering project cost as a criterion of project success, with respect to project success or project performance. This could be explained by the fact that some of the questionnaire respondents were previously involved in construction projects where risk reduction or quality improvement was relatively more important than project cost management. 


\section{Conclusion}

Although many studies of construction project costs have been conducted, the influencing factors of the project cost vary considerably across countries. The study focuses on identifying significant cost-influencing factors for improving project cost performance. The data were collected from a questionnaire survey circulated across construction institutions in New Zealand. The analysis has been formalized by a structural equation model, and the estimation has been performed by regarding the GME and Bayesian methods. Both methods can provide satisfied results. The results of this study explored the significant effects of the construction project system and economic-market climate on the construction project cost, whereas external environment had not effect. Moreover, an economic-market climate can significantly influence a construction project system. Additionally, the external environment has a significant effect on the economic-market climate.

The advantage of the GME and Bayesian estimation methods are highlighted. In this study, a novel estimation method for the structural equation model based on the generalized maximum entropy (GME) method was proposed. The proposed method takes advantage of the benefits of the entropy-based estimation method such as no requirement of distribution assumption (distribution free) and excellent work with a small sample. The results suggest that using the GME method in a structural equation model is a useful alternative to the covariance SME, especially when only a small sample is available. The GME method usually produces small standard errors. It provides good global criterion of a model fit-normalized entropy index.

This paper provided a comprehensive introduction to the Bayesian technique for structural equation modelling. Although receiving increased attention from other research fields, the application of Bayesian SEM in the construction literature is still highly limited. This study highlights the merits of the Bayesian SEM and illustrates its distinctiveness from the traditional covariance-based SEM approach. Overall, there are three reasons why construction researchers may select Bayesian SEM over covariance-based SEM. First, as addressed previously, the Bayesian SEM is able to accommodate small sample sizes. Second, based on proper identification of prior information and Markov Chain Monte Carlo simulation, the Bayesian technique can generate more accurate parameter estimates. Third, Bayesian SEM can provide more accurate and less sensitive fit measures. Despite the power of the Bayesian SEM, naive application of it should not be encouraged. According to [105], without a good understanding of Bayesian SEM, its application can be dangerous, especially in terms of interpreting Bayesian features and outputs. Moreover, the selection of appropriate priors is also an empirical issue in Bayesian SEM. Conducting comparison analysis to check the results across different prior choices could be a further research area.

These findings would contribute to both research and construction industry in cost management for the New Zealand construction industry and would also provide useful information for foreign firms that intend to develop construction projects in New Zealand. The industry professionals can formulate cost management strategies based on the findings of this study. Moreover, the results also form the foundation for further project management studies. In addition, the provided innovative statistical analysis methods also advance the application of structural equation modelling in construction research.

Three implications can be obtained from the results. First, the study validates that category of the cost-influencing factors in New Zealand is meaningful. Therefore, there is a need to group the influencing factors before investigating and assessing their impacts on the construction project cost, as different groups of influencing factors correlate differently with the construction project cost. Second, the developed structural model improves the understanding of the project context. The developed model can help industry professionals better understand the project context, and the risks related to the project cost. It helps decision makers to identify the cost-related risks prior to the project construction, and thus can help them avoid or alleviate those risks. For example, a possible way to properly manage the construction project cost is to properly control the significant cost-influencing factors. The results also validate the innovative statistical methods.

\section{Data Availability}

Data used in this study can be provided as request.

\section{Conflicts of Interest}

The authors declare no conflicts of interest.

\section{Acknowledgments}

The authors would like to thank the China Scholarship Council (CSC) for its support through the research project and the Massey University. The authors would like to thank Association of Consulting Engineers of New Zealand (ACENZ), New Zealand Institution of Architects (NZIA), and New Zealand Institute of Quantity Surveyors (NZIQS) for providing data to conduct this research. In addition, The authors would like to thank all Practitioners who contribute in this project. This research was funded by China Scholarship Council (Grant no. 201206130069) and Massey University (Grant no. 09166424). The APC is funded by the both grants.

\section{References}

[1] J. S. Shane and D. Gransberg, Project Management Strategies for Complex Projects, National Academy of Sciences, Iowa, USA, 2012.

[2] J. Kujala, T. Brady, and J. Putila, "Challenges of cost management in complex projects," International Journal of Business and Management, vol. 9, no. 11, pp. 48-57, 2014.

[3] L. D. Nguyen, L. Le-Hoai, D. Q. Tran, C. N. Dang, and C. V. Nguyen, "Fuzzy AHP with applications in evaluating construction project complexity," in Fuzzy Hybrid Computing 
in Construction Engineering and Management, A. R. Fayek, Ed., Emerald Publishing Limited, UK, pp. 277-299, 2018.

[4] S. M. El-Sayegh, "Risk assessment and allocation in the UAE construction industry," International Journal of Project Management, vol. 26, no. 4, pp. 431-438, 2008.

[5] P. Sridarran, K. Keraminiyage, and L. Herszon, "Improving the cost estimates of complex projects in the project-based industries," Built Environment Project and Asset Management, vol. 7, no. 2, pp. 173-184, 2017.

[6] A. Rauzana, "Uncertainty variables on cost estimation in project construction," IOSR Journal of Business and Management, vol. 20, no. 1, pp. 80-86, 2018.

[7] RBNZ, Housing and Dairy Risks to Financial Stability, Reserve Bank of New Zealand, Wellington, NZ, USA, 2016.

[8] R. Fellows and A. Liu, Research Methods for Construction, Wiley-Blackwell, Oxford, UK, 2008.

[9] S.-Y. Lee and X.-Y. Song, "Bayesian structural equation model," Wiley Interdisciplinary Reviews: Computational Statistics, vol. 6, no. 4, pp. 276-287, 2014.

[10] A. G. Assaf, H. Oh, and M. G. Tsionas, "Unobserved heterogeneity in hospitality and tourism research," Journal of Travel Research, vol. 55, no. 6, pp. 774-788, 2016.

[11] P. E. Rossi and G. M. Allenby, "Bayesian statistics and marketing," Marketing Science, vol. 22, no. 3, pp. 304-328, 2003.

[12] A. Golan, G. Judge, and D. Miller, Maximum Entropy Econometrics: Robust Estimation with Limited Data, Wiley, New York, NY, USA, 1996.

[13] A. Crisci, "Estimation methods for the structural equation models: maximum likelihood, partial least squares and generalized maximum entropy," Journal of Applied Quantitative Methods, vol. 7, no. 2, pp. 1-17, 2012.

[14] E. T. Jaynes, "Information theory and statistical mechanics. II," Physical Review, vol. 108, no. 2, pp. 171-190, 1957.

[15] K. C. Iyer and K. N. Jha, "Factors affecting cost performance: evidence from Indian construction projects," International Journal of Project Management, vol. 23, pp. 283-295, 2004.

[16] L. Y. Shen, G. W. C. Wu, and C. S. K. Ng, "Risk assessment for construction joint ventures in China," Journal of Construction Engineering and Management, vol. 127, no. 1, pp. 76-81, 2001.

[17] R. Kangari, "Risk management perceptions and trends of U.S. Construction," Journal of Construction Engineering and Management, vol. 121, no. 4, pp. 422-429, 1995.

[18] N. A. Kartam and S. A. Kartam, "Risk and its management in the Kuwaiti construction industry: a contractors' perspective," International Journal of Project Management, vol. 19, no. 6, pp. 325-335, 2001.

[19] D. Fang, M. Li, P. S.-W. Fong, and L. Shen, "Risks in Chinese construction market-contractors' perspective," Journal of Construction Engineering and Management, vol. 130, no. 6, pp. 853-861, 2004.

[20] F. Y. Y. Ling and L. Hoi, "Risks faced by Singapore firms when undertaking construction projects in India," International Journal of Project Management, vol. 24, no. 3, pp. 261-270, 2006.

[21] X. W. Zou, G. Zhang, and J.-Y. Wang, "Identifying key risks in construction projects: life cycle and stakeholder perspectives," International Journal of Construction Management, vol. 9, no. 1, pp. 1-14, 2014.

[22] O. Taylan, A. O. Bafail, R. M. S. Abdulaal, and M. R. Kabli, "Construction projects selection and risk assessment by fuzzy AHP and fuzzy TOPSIS methodologies," Applied Soft Computing, vol. 17, no. 6, pp. 105-116, 2014.
[23] L. M. Khodeir and A. H. M. Mohamed, "Identifying the latest risk probabilities affecting construction projects in Egypt according to political and economic variables. From January 2011 to January 2013," HBRC Journal, vol. 11, no. 1, pp. 129-135, 2015.

[24] KPMG, Singapore Risk Management Survey: Trends, Benefits and Challenges of the Risk Management Experience in Singapore, KPMG, Singapore, 2006.

[25] S. Qian, "Rethinking the implementation of project management: a value adding path map approach," International Journal of Project Management, vol. 29, no. 3, pp. 295-302, 2011.

[26] P. Garg and A. Garg, "Factors influencing ERP implementation in retail sector: an empirical study from India," Journal of Enterprise Information Management, vol. 27, no. 4, pp. 424-448, 2014.

[27] V. B. Gargeya and C. Brady, "Success and failure factors of adopting SAP in ERP system implementation," Business Process Management Journal, vol. 11, no. 5, pp. 501-516, 2005.

[28] S. Biazzo, "Process mapping techniques and organisational analysis," Business Process Management Journal, vol. 8, no. 1, pp. $42-52,2002$.

[29] M. D. Okrent and R. J. Vokurka, "Process mapping in successful ERP implementations," Industrial Management \& Data Systems, vol. 104, no. 8, pp. 637-643, 2004.

[30] S. M. Huang, I. C. Chang, S. H. Li, and M. T. Lin, "Assessing risk in ERP projects: identify and prioritize the factors," Industrial Management \& Data Systems, vol. 104, no. 8, pp. 681-688, 2004.

[31] M. Bharat, V. Kumar, and U. Kumar, "Delineating the ERP institutionalization process: go live to effectiveness," Business Process Management Journal, vol. 16, no. 4, pp. 744-771, 2010.

[32] D. Aloini, R. Dulmin, and V. Mininno, "Risk management in ERP project introduction: review of the literature," Information \& Management, vol. 44, no. 6, pp. 547-567, 2007.

[33] S. H. Lim and C. E. Koh, "RFID implementation strategy: perceived risks and organizational fits," Industrial Management and Data Systems, vol. 109, no. 8, pp. 1017-1036, 2009.

[34] D. Baloi and A. D. F. Price, "Evaluation of global risk factors affecting cost performance in Mozambique," in COBRA Conference, 2001.

[35] D. Nasir, B. McCabe, and L. Hartono, "Evaluating risk in construction-schedule model (ERIC-S): construction schedule risk model," Journal of Construction Engineering and Management, vol. 129, no. 5, pp. 518-527, 2003.

[36] C. Karaveg, N. Thawesaengskulthai, and A. Chandrachai, "A combined technique using SEM and TOPSIS for the commercialization capability of R\&D project evaluation," Decision Science Letters, vol. 4, pp. 379-396, 2015.

[37] D. Kirikkaleli, "Interlinkage between economic, financial, and political risks in the Balkan countries: evidence from a panel cointegration," Eastern European Economics, vol. 54, no. 3, pp. 208-227, 2016.

[38] R. Torabi, M. Eshraghi, and E. Nagheli, "Financial stability and economic performance in OPEC countries: an approach to co-integration methods," International Journal of Management, Accounting \& Economics, vol. 4, no. 1, pp. 56-65, 2017.

[39] Y.-M. Cheng, "An exploration into cost-influencing factors on construction projects," International Journal of Project Management, vol. 32, no. 5, pp. 850-860, 2014. 
[40] L. S. Aikin, J. A. Stein, and P. M. Bentler, "Structural equation analysis of clinical sub-population differences and comparative treatment outcomes: characterizing the daily lives of drug addicts," Journal of Consulting and Clinical Psychology, vol. 62, pp. 488-499, 1994.

[41] M. Ball, M. Farshchi, and M. Grilli, "Competition and the persistence of profits in the UK construction industry," Construction Management and Economics, vol. 18, no. 7, pp. 733-745, 2000.

[42] H. H. Frederick and D. F. Kuratko, Entrepreneurship, AsiaPacific Edition, Sydney, Australia, 2nd edition, 2010.

[43] Y.-H. Chiang, B.-S. Tang, and W.-Y. Leung, "Market structure of the construction industry in Hong Kong," Construction Management and Economics, vol. 19, no. 7, pp. 675-687, 2001.

[44] X. Zhang, "Financial viability analysis and capital structure optimization in privatized public infrastructure projects," Journal of Construction Engineering and Management, vol. 131, no. 6, pp. 656-668, 2005.

[45] E. Öcal, E. L. Oral, and E. Erdis, "Crisis management in Turkish construction industry," Building and Environment, vol. 41, no. 11, pp. 1498-1503, 2006.

[46] D. Disatnik and Y. Steinhart, "Need for cognitive closure, risk aversion, uncertainty changes, and their effects on investment decisions," Journal of Marketing Research, vol. 52, no. 3, pp. 349-359, 2015.

[47] D. Baloi and A. D. F. Price, "Modelling global risk factors affecting construction cost performance," International Journal of Project Management, vol. 21, no. 4, pp. 261-269, 2003.

[48] D. B. Ashley and J. J. Bonner, "Political risks in international construction," Journal of Construction Engineering and Management, vol. 113, no. 3, pp. 447-467, 1987.

[49] R. Kangari and C. L. Lucas, Managing International Operations: A Guide for Engineers, Architects and Construction Managers, ASCE Press, Virginia, USA, 1997.

[50] D. B. Rosenbaum, "Questions hamper deals," Engineering News Record, vol. 24, no. 11, 1997.

[51] N. J. Lavingia, "Improve profitability through effective project management and TCM," Cost Engineering, vol. 45, no. 11, pp. 22-24, 2003.

[52] M. Kapelko, A. Oude Lansink, and S. E. Stefanou, “Assessing dynamic inefficiency of the Spanish construction sector preand post-financial crisis," European Journal of Operational Research, vol. 237, no. 1, pp. 349-357, 2014.

[53] M. Arnold, A. F. Wagner, and R. Westermann, "Growth options, macroeconomic conditions, and the cross section of credit risk," Journal of Financial Economics, vol. 107, no. 2, pp. 350-385, 2013.

[54] Z. Yildirim and M. Ivrendi, "Exchange rate fluctuations and macroeconomic performance," Journal of Economic Studies, vol. 43, no. 5, pp. 678-698, 2016.

[55] J. Aizenman, B. Pinto, and V. Sushko, "Financial sector ups and downs and the real sector in the open economy: up by the stairs, down by the parachute," Emerging Markets Review, vol. 16, pp. 1-30, 2013.

[56] R. Mirdala, "Financial integration and financial deepening in the selected European transition economies," Journal of Applied Economic Sciences, vol. 4, no. 6, pp. 419-433, 2008.

[57] ICMS, Global Consistency in Presenting Construction Costs, International Construction Measurement Standards., London, UK, 2017.

[58] M. Trabelsi and M. Cherif, "Capital account liberalization and financial deepening: does the private sector matter?" The
Quarterly Review of Economics and Finance, vol. 64, pp. 141-151, 2017.

[59] C. Benson, E. Clay, F. V. Michael, and A. W. Robertson, Dominica: Natural Disasters and Economic Development in a Small Island State, The World Bank, Washington, DC, USA, 2001.

[60] B. Sisk and C. L. Bankston III, "Hurricane katrina, a construction boom, and a New labor force: latino immigrants and the New orleans construction industry, 2000 and 2006-2010," Population Research and Policy Review, vol. 33, no. 3, pp. 309-334, 2013.

[61] P. V. Marsden and J. D. Wright, Handbook of Survey Research, Emerald Group Publishing Ltd, London, UK, 2010.

[62] P. Chen and J. Wang, "Application of a fuzzy AHP method to risk assessment of international construction projects," in Proceedings of the International Conference on Electronic Commerce and Business Intelligence, Beijing, China, 2009.

[63] B. Xiong, M. Skitmore, B. Xia, M. A. Masrom, K. Ye, and A. Bridge, "Examining the influence of participant performance factors on contractor satisfaction: a Structural Equation Model," International Journal of Project Management, vol. 32, no. 3, pp. 482-491, 2014.

[64] L. A. Aday and L. J. Cornelius, Designing and Conducting Health Surveys: A Comprehensive Guide, John Wiley \& Sons, New York, NY, USA, 2011.

[65] M. D. Kaplowitz, T. D. Hadlock, and R. Levine, "A comparison of web and mail survey response rates," Public Opinion Quarterly, vol. 68, no. 1, pp. 94-101, 2004.

[66] C. E. Shannon, "A mathematical theory of communication," Bell System Technical Journal, vol. 27, no. 3, pp. 379-423, 1948.

[67] E. T. Jaynes, "Information theory and statistical mechanics," Physical Review, vol. 106, no. 4, pp. 620-630, 1957.

[68] A. Hernando, A. Plastino, and A. R. Plastino, "MaxEnt and dynamical information," European Physical Journal B, vol. 85 , no. 5 , p. 147, 2012.

[69] A. Hernando and A. Plastino, "Variational principle underlying scale invariant social systems," The European Physical Journal B, vol. 85, no. 293, pp. 1-6, 2012.

[70] A. Hernando, R. Hernando, A. Plastino, and A. R. Plastino, "The workings of the maximum entropy principle in collective human behaviour," Journal of The Royal Society Interface, vol. 10, no. 78, pp. 1-11, 2013.

[71] T. Squartini and D. Garlaschelli, Maximum-Entropy Networks, Springer, Berlin, Germany, 2017.

[72] E. Karmeshu, Maximum Entropy Principle and Emerging Applications, Springer, Berlin, Germany, 2003.

[73] P. Dua, "Macroeconomic modelling and bayesian methods," Journal of Quantitative Economics, vol. 15, no. 2, pp. 209226, 2017.

[74] X.-Y. Song and S.-Y. Lee, "A tutorial on the Bayesian approach for analyzing structural equation models," Journal of Mathematical Psychology, vol. 56, no. 3, pp. 135-148, 2012.

[75] L. Kogan, Small-sample Inference and Bootstrap, MIT, Sloan, USA, 2010.

[76] B. Muthén and T. Asparouhov, "Bayesian structural equation modeling: a more flexible representation of substantive theory," Psychological Methods, vol. 17, no. 3, pp. 313-335, 2012.

[77] D. K. Sari, N. W. S. Wardhani, and S. Astutik, "Parameter estimation of structural equation modeling using bayesian approach," Cauchy, vol. 4, no. 2, pp. 86-94, 2016

[78] H. W. Marsh, A. J. S. Morin, P. D. Parker, and G. Kaur, "Exploratory Structural Equation Modeling: an integration 
of the best features of exploratory and confirmatory factor analysis," Annual Review of Clinical Psychology, vol. 10, no. 1, pp. 85-110, 2014.

[79] W. R. Stromeyer, J. W. Miller, R. Sriramachandramurthy, and R. DeMartino, "The prowess and pitfalls of bayesian structural equation modeling," Journal of Management, vol. 41, no. 2, pp. 491-520, 2015.

[80] T. Asparouhov, B. Muthén, and A. J. S. Morin, "Bayesian structural equation modeling with cross-loadings and residual covariances," Journal of Management, vol. 41, no. 6, pp. 1561-1577, 2015.

[81] S.-Y. Lee, X.-Y. Song, and N.-S. Tang, "Bayesian methods for analyzing structural equation models with covariates, interaction, and quadratic latent variables," Structural Equation Modeling: A Multidisciplinary Journal, vol. 14, no. 3, pp. 404-434, 2007.

[82] J. F. Hair, W. C. Black, B. J. Babin, and R. E. Anderson, Multivariate Data Analysis, Pearson Education International, New Jersey, NJ, USA, 2010.

[83] A. D. Al-Nasser, "Customer satisfaction measurement models: generalised maximum entropy approach," Pakistan Journal of Statistics, vol. 19, no. 2, pp. 213-226, 2003.

[84] I. Ntzoufras, Bayesian Modeling in WinBugs, John Wiley \& Sons, New York, NY, USA, 2009.

[85] S. Amato, V. EspositoVinzi, and M. Tenenhaus, A Global Goodness-Of-Fit Index for PLS Structural Equation Modeling; Oral Communication to PLS Club, HEC School of Management, France, 2004.

[86] A. Golan, G. George, and D. Miller, Maximum Entropy Econometrics, Wiley, London, UK, 1996.

[87] A. Golan, L. S. Karp, and J. M. Perloff, "Estimating Coke's and Pepsi's price and advertising strategies," Journal of Business \& Economic Statistics, vol. 18, pp. 398-409, 2001.

[88] A. Gelman and D. B. Rubin, "Inference from iterative simulation using multiple sequences," Statistical Science, vol. 7, no. 4, pp. 457-472, 1992.

[89] D. J. Spiegelhalter, N. G. Best, B. P. Carlin, and A. van der Linde, "Bayesian measures of model complexity and fit," Journal of the Royal Statistical Society: Series B (Statistical Methodology), vol. 64, no. 4, pp. 583-639, 2002.

[90] J. Holtmann, T. Koch, K. Lochner, and M. Eid, "A Comparison of ML, WLSMV, and Bayesian methods for multilevel Structural Equation Models in small samples: a simulation study," Multivariate Behavioral Research, vol. 51, no. 5, pp. 661-680, 2016.

[91] S. Sinharay, "Experiences with Markov chain Monte Carlo convergence assessment in two psychometric examples," Journal of Educational and Behavioral Statistics, vol. 29, no. 4, pp. 461-488, 2004.

[92] J. M. Bernardo, J. O. Berger, A. P. Dawid, and A. F. M. Smith, Bayesian Statistics, Oxford University Press, London, UK, 1992.

[93] W. R. Gilks, S. Richardson, and D. J. Spiegelhalter, Markov Chain Monte Carlo in Practice, Chapman \& Hall, New York, NY, USA, 1996.

[94] R. Levy, "Bayesian data-model fit assessment for structural equation modeling," Structural Equation Modeling: A Multidisciplinary Journal, vol. 18, no. 4, pp. 663-685, 2011.

[95] R. H. Hoyle, Structural Equation Modeling: Concepts, Issues, and Applications, Sage, Thousand Oaks, CA, USA, 1995.

[96] R. E. Kass and A. E. Raftery, "Bayes factors," Journal of the American Statistical Association, vol. 90, no. 430, pp. 773795, 1995.
[97] D. K. H. Chua, Y. C. Kog, and P. K. Loh, "Critical success factors for different project objectives," Journal of Construction Engineering and Management, vol. 125, no. 3, pp. 142-150, 1999.

[98] D. J. Lowe, M. W. Emsley, and A. Harding, "Relationships between total construction cost and project strategic, site related and building definition variable," Journal of Financial Management of Property and Construction, vol. 11, no. 3, pp. 165-180, 2006.

[99] P. Krishnamurthy, "Banking deregulation, local credit supply, and small-business growth," The Journal of Law and Economics, vol. 58, no. 4, pp. 935-967, 2015.

[100] S. M. Wachter, "Credit supply and housing prices in national and local markets," Public Finance Review, vol. 44, no. 1, pp. 6-21, 2016.

[101] A. J. Shenhar, "One size does not fit all projects: exploring classical contingency domains," Management Science, vol. 47, no. 3, pp. 394-414, 2001.

[102] A. J. Shenhar and D. Dvir, Reinventing Project Management: The Diamond Approach to Successful Growth \& Innovation, Harvard Business School Press, Watertown, MA, USA, 2007.

[103] H. Priemus, B. Flyvbjerg, and B. Wee, Decision-making on Mega-Projects: Cost-Benefit Analysis, Planning and Innovation, Edward Elgar Publishing, London, UK, 2008.

[104] T. Cooke-Davies, L. Crawford, J. R. Patton, C. Stevens, and T. M. Williams, Aspects of Complexity: Managing Projects in a Complex World, Project Management Institute: Newtown Square, Newton Square, PA, USA, 2011.

[105] S. Depaoli and R. van de Schoot, "Improving transparency and replication in Bayesian statistics: the WAMBS-Checklist," Psychological Methods, vol. 22, no. 2, pp. 240-261, 2017. 